Portland State University

PDXScholar

4-1-1969

\title{
Measuring trainee comprehension of casework relationship in a public welfare orientation program
}

\author{
Margaret Berweger \\ Portland State University \\ Glen R. Dugger \\ Dennis C. Florendo \\ Patricia Harmony \\ Jerry L. Juve
}

See next page for additional authors

Follow this and additional works at: https://pdxscholar.library.pdx.edu/open_access_etds Let us know how access to this document benefits you.

\section{Recommended Citation}

Berweger, Margaret; Dugger, Glen R.; Florendo, Dennis C.; Harmony, Patricia; Juve, Jerry L.; Plant, Sherien E.; Schiessl, Richard C.; and Singer, Oma W., "Measuring trainee comprehension of casework relationship in a public welfare orientation program" (1969). Dissertations and Theses. Paper 868.

\section{$10.15760 /$ etd. 868}

This Thesis is brought to you for free and open access. It has been accepted for inclusion in Dissertations and Theses by an authorized administrator of PDXScholar. For more information, please contact pdxscholar@pdx.edu. 


\section{Author}

Margaret Berweger, Glen R. Dugger, Dennis C. Florendo, Patricia Harmony, Jerry L. Juve, Sherien E. Plant, Richard C. Schiessl, and Oma W. Singer 
AN ABSTRACT OF THE GROUP PROJECT OF Margaret Berweger, et al. for the Master of Social Work presented April 15, 1969.

Title: Measuring Trainee Comprehension of Casework Relationship in a Public Welfare Orientation Program

APPROVED BY MEMBERS OF THE GROUP PROJECT COMMITTEE:

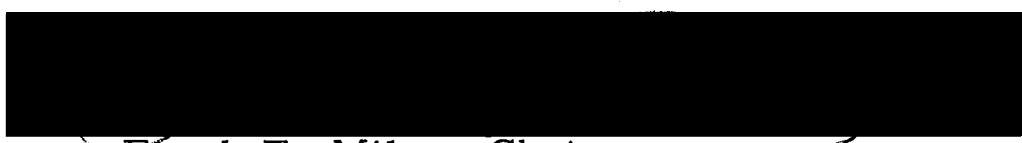

Frank F. Miles, Chairman

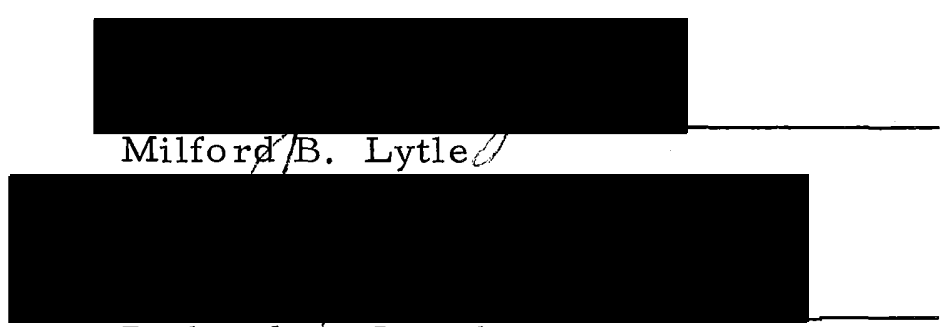

Richard L. Leitch

This study was undertaken as a first step in measuring effectiveness of the Oregon State Public Welfare Orientation Center program in teaching principles of the casework relationship as conceptualized by Felix P. Biestek. This anticipated the development of a reasonably reliable instrument, improvement and validation of which would be undertaken in a subsequent study.

The population tested was made up of male and female college graduates, newly hired by the State, who were then entering a four 
week orientation program for caseworkers. Their education and experience varied, but all had passed the State Civil Service examination for this position.

Learning was tested on concepts of purposeful expression of feelings, controlled emotional involvement, acceptance, individualization, non-judgmental attitude, client self-determination, and confidentiality.

From constructed test questions, two tests were formulated and administered in a pretest. Following evaluation of the pretest, the questions were revised and used for two versions of the test which were administered to two orientation classes before and after training. Internal and inter-test reliability, item analysis, and sensitivity were determined for the instrument. Pre-training and post-training differences within and between groups were estimated statistically.

Statistical analysis of the data indicated that the tests were moderately reliable both internally and with each other. The testing instruments were able to discriminate between before and after scores. There was significant learning in that scores were higher after completion of the training session beyond chance. 
MEASURING TRAINEE COMPREHENSION OF CASEWORK

RELATIONSHIP IN A PUBLIC WELFARE

ORIENTATION PROGRAM

by

MARGARET BERWEGER

GLEN R. DUGGER

DENNIS C. FLORENDO

PATRICIA HARMONY
JERRY L. JUVE

SHERIEN E. PLANT

RICHARD C. SCHIESSL

OMA W. SINGER

A group project submitted in partial fulfillment of the requirements for the degree of

MASTER OF SOCIAL WORK

Portland State University

1969 
TO THE OFFICE OF GRADUATE STUDIES:

The members of the Committee approve the group project of Margaret Berweger, et al. presented April 15, 1.969.

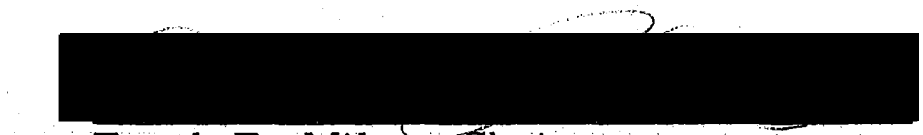

Frank F. Miles, Chairman

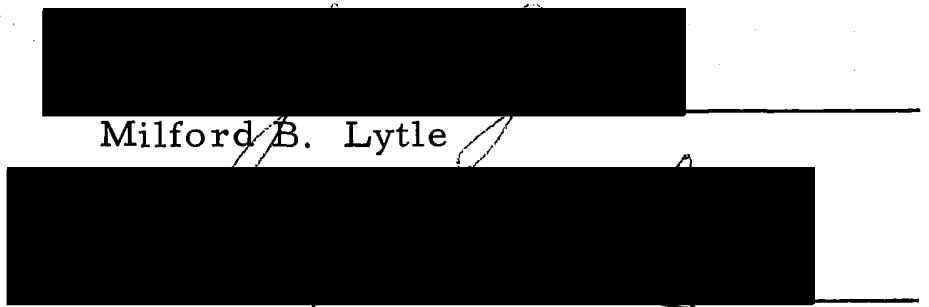

Richard L. Leitch

APPROVED:

Daniel E. Jerrings, Acting Dean, School of Social Work

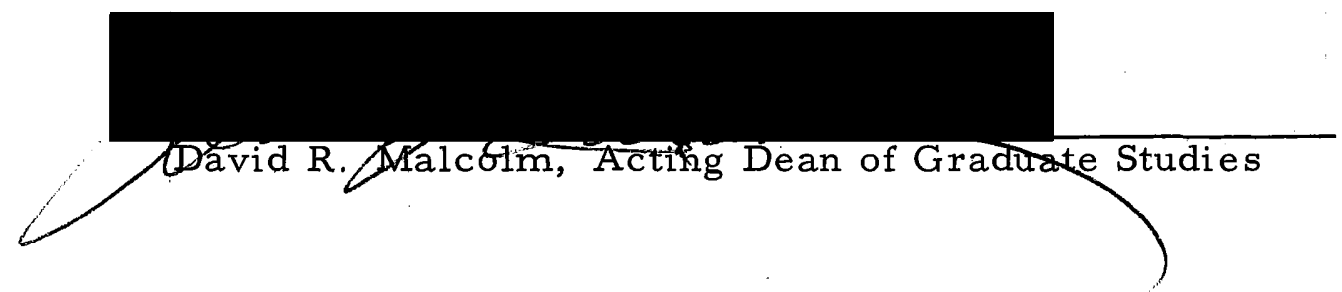

April 20, 1969 
TABLE OF CONTENTS

PAGE

LIST OF TABLES . . . . . . . . . . . . . . . V V

CHAPTER

I THE PROBLEM AND ITS IMPORTANCE . . . 1

Purpose . . . . . . . . . . . . . . 1

The Setting . . . . . . . . . . . 2

Principles of the Casework Relationship . 6

Literature Reviewed ......... . 12

II TEST CONSTRUCTION .......... 21

Formulation of Questions ....... 23

General Testing Design . . . . . 25

Purposes of the Pretest. . . . . . . 28

Administration of the Pretest . . . . 29

Analysis of the Pretest. . . . . . . 30

Reformulation of the Pretest . . . . 34

Testing the Experimental Groups . . . 35

III FINDINGS AND CONCLUSIONS . . . . . . 37

Findings ............. . . 37 


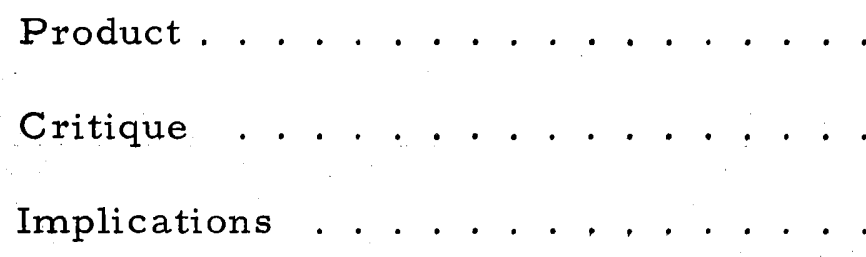

Need for Further Research . . . . . .

BIBLIOGRAPHY . . . . . . . . . . . . . . . . .

APPENDICES
A GUIDELINES FOR CONSTRUCTION OF QUESTIONS . . . . . . . . . . . .
B ILLUSTRATIVE QUESTIONS USED IN TEST.
C INSTRUCTION SHEET. . . . . . . . . .
D VERBAL INSTRUCTIONS FOR PRETEST .
E POST-TEST QUESTIONNAIRE ........ 


\section{LIST OF TABLES}

TABLE

I Testing Plan for Administering Test to

Sessions I and II . . . . . . . . . . 26

II Actual Testing Procedure . . . . . . . . 27

III Pretest Efficiency Data. . . . . . . . 33

IV Ordering of Items in Test Revision . . . . . 35

V Errors on Tests for Experimental Groups

Before and After Training........ 38

VI Time Range and Mean for Two Experimental

Groups . . . . . . . . . . . . 


\section{CHAPTER I}

\section{THE PROBLEM AND ITS IMPORTANCE}

With the increasing recognition at all levels of our society that more adequate provisions must be made for meeting the social welfare needs of a rapidly growing and changing population, the demand for social work services has far exceeded the capacity of existing institutions to supply the needed trained personnel. The schools of social work have been able to supply only a limited number of profes sional workers to provide direct services. In order to meet the existing need it has been incumbent upon public and private agencies to initiate their own training programs. Questions have arisen about the effectiveness of such agencies in providing an introductory knowledge of casework principles and the application of these principles in providing direct services.

\section{PURPOSE}

The main purpose of this study is to assess the effectiveness of teaching certain casework principles in a public welfare orientation center program. The impetus for this research was provided by a request to the School of Social Work, Portland State University, 
from the Staff Development Division of the Oregon State Public Welfare Commission suggesting that graduate students undertake a study to evaluate the effectiveness of the State Orientation Center in teaching basic casework concepts and to develop a better test for future use. Research was undertaken to develop a test instrument to measure knowledge and practical application of these concepts.

\section{THE SETTING}

The subjects studied, aside from a group for pretesting, were all members of two training sessions totaling sixty-six persons enrolled in the Orientation Center training program during the summer of 1968. There were twenty-nine men and thirty-seven women in two classes. The age range was from twenty-one to fifty-six years and prior training and experience varied from B. A. without experience to M.S. W. with casework experience. College majors of these trainees included eighteen in Sociology, twelve in Social Sciences, eleven in Psychology, and twenty-nine in a variety of eleven different areas including Education, Business Administration and Home Economics.

There are certain minimum requirements for acceptance into the program. The trainee must have passed an Oregon State civil service examination for caseworker or social worker, have been accepted for employment by a County Public Welfare Department, have 
a college degree, and have passed a graded oral interview.

Orientation centers have been established throughout the United States to implement the Federal Social Security Amendments of 1962 which require state agencies administering public assistance programs to include an organized training plan for workers giving service. One of Oregon's plans has been to provide a designated period of orientation for new employees, as well as in-service training.

The Oregon State Orientation Center for training new caseworkers is located in Oregon City, Oregon, and it trains for County Welfare Departments throughout the State. One of the main purposes of the Orientation Center is to facilitate a better understanding, on the part of the caseworker, of public welfare's dual responsibility to the public and to the recipient. It has a responsibility to the public to see that policies and regulations are followed in order that there be adequate accountability for expenditure of funds. Public welfare also has the responsibility of assuring clients that their dignity and rights will be respected. This implies acceptance and understanding of variations in individual attitudes and behavior patterns. Help must be provided in a way which will supplement and develop individual resources in a constructive manner consistent with the agency goal of developing self-care and strengthening family life.

In order for the above responsibilities to be carried out, the Orientation Center must impart to caseworkers an understanding of 
the basic facts about the components of the agency program and its goals, the eligibility factors and the social services provided. Caseworkers must have an opportunity to become familiar with social work philosophy, to acquire a beginning knowledge of the techniques of helping and to develop a beginning skill in applying this knowledge. In addition, caseworkers are expected to acquire an understanding of the overall objectives of public assistance based on the historical development of welfare programs, with emphasis on the Social Security Act, and the relationship of federal and state agencies to county programs.

Under trained and experienced supervisor-teachers, daily classes are held for a four-week orientation session. The curriculum includes study of manuals, use of forms, readings about the principles and techniques of casework, discussion of case material, work on active cases, field trips, and guest speakers. This program can give caseworkers only a beginning understanding of their job. Training is a process which will continue for them long after they have left the Orientation Center.

The Staff Development Division, after careful study, agreed with others involved in training that there was a great need for a better understanding on the part of the trainees of the concept "relationship" in casework. Lancelot (1, p. 263) indicates that special attention should be given to the worker's beginning ability to 
relate to and be interested in people. Weschner-Salzberger, et al. (2, p. 75) stress the importance of the professional relationship in their outline of a short-term staff development project for social welfare workers.

In her article "Training Goals in Public Assistance," Wolfe (3, p. 71 ) states that one of the goals is to insure the availability of workers who, in the course of providing financial assistance, have knowledge and skill to provide social services which are appropriate to the needs and wishes of the client. She goes on to say that training should be offered to insure that caseworkers have:

1. Knowledge of the society being served

2. Understanding of the relationship of the se goals to our political, social, economic structure, and understanding of the changing forces that affect the individual, the community, and the society as a whole

3. Knowledge of normal human growth and personality development

4. Knowledge of behavior that is abnormal, and, to the same degree, how some people may react in times of stress

5. Capacity to respond with empathy

6. Ability to evaluate controversial situations

7. Ability to obtain facts, to make an objective analysis of them, and to reach decisions

Implicit in the above is the concept "relationship" which, as conceptualized by Biestek (4, p. 4), is the most important factor in the casework process. 


\section{PRINCIPLES OF THE CASEWORK RELATIONSHIP}

It was the teaching of casework principles in the training program which the staff at the Orientation Center was particularly interested in having evaluated at this time. It is recognized that other aspects of the training program are important but the phase of orientation undertaken for study was the casework relationship. Casework principles were taught within the framework of Biestek's conception of the casework relationship. With this in mind the test was constructed based on Biestek and the understanding of test items would depend upon a comprehension of the carefully detailed elements of the relationship.

Biestek (4, p. 14) identifies seven basic human needs which he feels are common to all persons with problems. These are:

1. The need to be dealt with as an individual rather than a case, a type, or a category.

2. The need to express their feelings, both negative and positive.

3. The need to be accepted as a person of worth, a person with innate dignity, regardless of the person's dependency, weaknesses, faults or failures.

4. The need for a sympathetic understanding of and response to the feelings expressed.

5. The need to be neither judged nor condemned for the difficulty in which the client finds himself.

6. The need to make one's own choices and decisions concerning one's own life.

7. The need to keep confidential information about oneself as secret as possible. 
Biestek (5, p. 60) defines seven principles to which a caseworker must adhere in order to meet these basic needs of the client. These are: (1) Individualization, (2) Purposeful expression of feelings, (3) Controlled emotional involvement, (4) Acceptance, (5) Nonjudgmental attitude, (6) Client self-determination, and (7) Confidentiality.

Each principle will be discussed in detail. However, it is important to understand that these principles have a history in social thought. For example, in his doctoral dissertation entitled "Confidentiality in Social Work, "Alves (6) mentioned many authors who treated this subject going as far back as St. Thomas Aquinas. Gjenvick (7) goes even further into history in his article on selfdetermination.

In preparing his doctoral dissertation on client self-determination, Biestek (8) did an exhaustive study of casework literature from 1921 to 1950. From his research he developed his concept of the seven elements essential to the casework relationship. These were presented in summary form to the trainees at the Orientation Center using both Biestek's (4) book entitled "The Casework Relationship" and his article (5) entitled "An Analysis of the Casework Relationship." The elements will be discussed in the order in which they appeared in the article: 
1. Purposeful expression of feelings

2. Controlled emotional involvement

3. Acceptance

4. Individualization

5. Non-judgmental attitude

6. Client self-determination

7. Confidentiality

The first of Biestek's (5, p. 60) elements is the purposeful expression of feelings which he defined in this way:

. . The recognition of the client's need to express his feelings freely, especially his negative feelings. The caseworker listens purposefully, neither discouraging nor condemning the expression of these feelings, sometimes even actively stimulating and encouraging them, when they are therapeutically useful . . .

The author based this definition on the premise that man's psycho-social needs include sharing of experiences and seeking social approval and recognition. It is related to the client's need for acceptance and the need to become involved in the solution of his own problem.

Biestek saw certain limitations of the purposeful expression of feelings. First, the worker should not encourage the release of feelings with which his particular agency could not deal. Second, too early an expression of deep feeling could create an impasse in the client-worker relationship. Third, dependence upon the worker, which is generated by the expression of feelings, may result in overdependence. Fourth, the expression of feelings of hostility need to be understood but not necessarily encouraged. 
Biestek (5, p. 60) says "controlled emotional involvement is the caseworker's sensitivity to the client's feelings, an understanding of their meaning, and a purposeful, appropriate use of the worker's emotions in response to the client's feelings." He believes that the most important psychological element in the casework relationship is the caseworker's response to the client on the feeling level. He points out that the response is not necessarily verbal but primarily an internal response. He suggests that more attention needs to be given to the development of an appropriate feeling within the caseworker than to any specific way of expressing it.

In "The Casework Relationship" (4, p. 72) Biestek defines acceptance as:

. . a principle of action wherein the caseworker perceives and deals with the client as he really is, including his strength and weaknesses, his congenial and uncongenial qualities, his positive and negative feelings, his constructive and destructive attitudes and behavior, all the while maintaining a sense of the client's innate dignity and personal worth ...

He makes it clear that acceptance does not mean approval of deviant attitudes and behavior. Pertinent reality is seen as the object of acceptance rather than good behavior. The purpose of acceptance is therapeutic and thus a tool to aid the caseworker in understanding the client as he really is since it frees him from undesirable defenses. The client feels safe in revealing himself and is enabled to deal with his problems and himself in a more realistic way. 
Biestek's reasoning in formulating his concept of individualization came out of his recognition that client-focused modern casework relies upon the individual's own presentation of the problem. Diagnosis, treatment and treatment goals are dependent upon the uniqueness of each individual case. He (4, p. 25) defined individualization as follows:

Individualization is the recognition and understanding of each client's unique qualities, and the differential use of principles and methods in assisting each toward a better adjustment. Individualization is based upon the right of human beings to be individuals and to be treated not just as a human being, but as this human being with his personal differences.

Biestek saw each client as differing, in fact, from all others due to differences in individualized environment, heredity and life experiences and, therefore, needing different treatment plans to facilitate involvement of his resources and abilities to cope with his problems. Biestek went even further in putting forth the idea that each person is conscious of being unique and this awareness becomes paramount when the individual requests any type of assistance with his problems.

This concept leads to the non-judgmental attitude which is the fifth element of the relationship:

The non-judgmental attitude is based upon the conviction that the casework function precludes assigning guilt or innocence, or degree of client responsibility for causation of the problems or needs, but does include making evaluative judgments about the attitudes, standards, or actions of the client. 
It can be seen that Biestek's (5, p. 60) defintion of the nonjudgmental attitude is closely allied to his concept of acceptance. The former springs from the client's need not to. be seen as a weakling or the responsible cause for his predicament. The caseworker can arrive at an understanding of the client's problem without assigning blame. Biestek makes it clear that the non-judgmental attitude is not to be confused with indifference to social, legal and moral standards.

Biestek could find no comprehensive description of client selfdetermination. However, he found that similar concepts had been referred to by other writers using terms such as client-participation, self-direction, and a variety of related descriptive phrases. The client's freedom of choice and decision appeared to be the common denominator of these expressions. Biestek (8, p. 190) proposed that:

The minimal definition of the principle of client selfdetermination must include first, the proposition that the client has a right and a need to be free in making his decisions and choices; second, a recognition that this right is limited by the client's capacity for self-determination, by law and authority, by community standards and by agency function; and third, recognition of the caseworker's duty to respect that right and to help the client exercise it.

Implicit in the above concept are the beliefs that the human personality has strength and power for growth and change, that clients have a right to solve their own problems in their own way, and that they have a need to have this right recognized by the caseworker. 
Biestek (4, p. 60) defines confidentiality as "the preservation of secret information concerning the client which is disclosed in the professional relationship." He regards this as an ethical obligation of the caseworker and as essential for effective casework service. However, he acknowledges that the right to secrecy is not absolute. The caseworker is an agent of a social agency and it may be necessary to share information to insure better service to the client. The right to secrecy is also limited by law, the rights of others and the good of society as a whole.

\section{LITERATURE REVIEWED}

From the foregoing discussion of Biestek's seven elements of the casework relationship, it can be seen that there is much overlapping of concepts. He (4, p. 12) has defined casework broadly as

. . the dynamic interaction of attitudes and emotions between the caseworker and the client, with the purpose of helping the client achieve a better adjustment between himself and his environment.

He discussed the elements separately but acknowledged that they are not separable in reality as each implies the remaining elements. A defect in any of the elements would mean that a defect exists in the relationship itself.

It had to be borne in mind that the trainees at the Orientation Center would have been influenced significantly in developing their 
concepts of relationship by individual experiences, folk knowledge, and cultural factors. In addition they may have been previously exposed to concepts of relationship developed by many others in the field of social work such as Aptekar (9), Garrett (10), Hamilton (11), Hollis (12), and Perlman (13). Biestek's (8) doctoral dissertation explains the main points of agreement and disagreement on this subject. An additional comprehensive study bearing on this is the unpublished doctoral dissertation of Couillard (14) entitled "A Historical Study of the Concept of Relationship in Social Casework, 19171960."

In 1941, Aptekar (9, p. 48) set forth the idea that relationship is a general descriptive term for some of the simple developments that take place when two persons get together, and it differs from everyday life in that the professional relationship is more controlled and purposive. As such it is a means of carrying out function rather than an end in itself, .

In Irvine (15) all seven elements of Biestek are discussed without being labelled as such. She spoke of them in terms of behavior and approach and their importance in establishing and maintaining a relationship. Towle (16, p. 9) expressed relationship in this way: ". . through understanding the person's feelings we . . may through thus sharing his problem afford each individual a relationship which strengthens him." 
Much that has been written regarding each of the elements is implied or alluded to rather than specifically labelled. Thus there are many broad interpretations of each concept leading to overlapping and blurring among them. According to Perlman (13, p. 67) the casework relationship cannot be established without the purposeful expression of feelings, and she explains it this way:

It is when feelings are expressed, or when the caseworker reaches out to release them and they are responded to receptively, attentively, and sympathetically, that an emotional span is flung between client and caseworker which is the beginning of relationship.

Timms (17, p. 71) says that problem solving can only be effective if there is a clear understanding of the material on which they are to work. "This entails that the caseworker values the expression of the client's feelings." Daly (18, p. 114) suggests the importance of the worker being attuned to the client's non-verbal as well as his verbal expressions of feeling. Hollis (12, p. 97) points out the therapeutic importance of the purposeful expression of feelings but cautions that under some circumstances it should be held in check.

Without using the terminology of Biestek, a number of writers discuss the concept of controlled emotional involvement. Hamilton (19, p. 161) states that the worker must develop his own inner controls to avoid being personally involved in the client's problems and hence be in a better position to assist the client. Perlman (13, p. 71) saw the casework relationship beginning "... as the client shares 
some part of his problem and as the caseworker demonstrates that he is at one with the client. . . that he is feeling, not like him, but with him. " The attitudes presented to the client must include an awareness and control, on the part of the caseworker, of his own feelings so that he does not become engulfed in the client's feelings. Hollis (12, p. 153) believes that professional training and experience equip the caseworker with the ability to control emotional involvement while communicating acceptance and understanding to the client. McCormick (20, p. 23) wrote that "intelligent sympathy must be combined with professional distance... so that the caseworker can maintain the balance between nearness and remoteness... which relationship in casework demands."

The principle of acceptance has long been recognized as one of the basic ingredients of a successful relationship. Hamilton(11, p. 40) stresses the ability of the worker to accept the client's feelings in es tablishing a relationship. Perlman (13, p. 140) concurs saying:

It is this constancy of receptiveness and responsiveness fused with the objectivity and therapeutic intent demonstrated by the caseworker's behavior that helps the client to lower the barriers he may have erected in protection of his fears.

In addition she states that the quotation "nor heaven nor hell can his soul surprise" might well have been written of the caseworker. These ideas are in agreement with Biestek's concept that the client must be accepted as he really is. 
The role of the individual client in relation to the presenting problem is emphasized by many writers. Either directly, as Biestek does, or indirectly the idea is expressed that the unique qualities and strengths of the individual constitute the matrix of treatment and treatment planning. Perlman (13, p. 140) does not specifically use the term individualization but she does in more general terms emphasize the need for the caseworker to recognize a person as himself and in his way different from all others. Hollis (12, p. 189) suggests using observations of individual transactions as a tool for understanding the individual. She acknowledged the influence of Freud on the development of her conceptual framework. Such writers as Simcox (21), Meyer (22), and Siporin (23) have not specified the principle of individualization as a treatment requirement yet they indirectly acknowledge an awareness of such a principle in their diagnostic statements and treatment planning. These writers do not expressly state that it is the right of human beings to be treated as individuals, but their approaches are based on the "client's unique qualities!' referred to by Biestek (4, p. 14).

Hamilton (19, p. 159) has this to say regarding the nonjudgmental attitude:

Caseworkers have moved from intolerance of certain forms of conduct to tolerance, and finally toward understanding, which is neither tolerance nor intolerance. This attitude of detachment is one of the products of the scientific development of the nineteenth century and is not, as we sometimes imagine, wholly an innovation of psychiatry. 
She later points out that the client who has been accepted in a non-judgmental way by the caseworker may find it easier to accept himself. There is agreement with and comingling of principles set forth by Biestek in Hamilton's assertions. Similarly, Perlman (13, p. 79) exemplifies the overlapping of concepts in saying that:

- . the worker's acceptance and understanding of the naturalness of relationship distortion (rather than an accusation that the client is feeling or acting inappropriately) provide the necessary security for the client to face up to what he himself may then find foolish or inappropriate in his behavior and feeling.

Fisher et al. (24, p. 12) in their exploratory study of the use

of self-determination and confidentiality in casework concluded that:

There is general agreement in the literature that selfdetermination is to be considered a right of all individuals, at least in a democratic society. . . Self-determination is, however, not absolute and should be limited when it may be harmful to the individual or to the rights of others.

Soyer (25, p. 78) adds another dimension to the concept of selfdetermination in calling for more daring on the part of caseworkers in allying themselves with the aspirations of the client even when these seem beyond the reach of the client who runs the risk of failure. Soyer believes that self-determination includes the right to fail. Somewhat philosophically Gjenvick (7, p. 35) reflects that ". . even though the client should choose evil, it is better that he choose evil than that his choice be denied and that his essential humanity thereby be denied." 
There is no division among writers about the basic requirement of confidentiality in the casework relationship. It is stipulated in the professional Code of Ethics (26, p. 5). However, as Sprafkin (27, p. 87) expressed it, "Confidentiality is more than a general principle. It is a many faceted concept which must be tested, and retested, in relation to specific issues. "It is the responsibility of the caseworker to explain to the clients the limits of confidentiality in a particular agency setting. Perlman (13, p. 124) affirms that it is ". . . the client's right to determine whether or not he will share his need and wants with anyone outside the agency. . . and it is the caseworker's ethical obligation not arbitrarily to wrest that right from him."

A perusal of research topics undertaken in recent masters' theses and doctoral dissertations indicates that few have concentrated on the elements of the casework relationship. In addition to the works of Alves, Biestek, Fisher et al. , $(6,8,24)$ a recent study by Meyer (28) was completed in 1968 which explored the concept of client self-determination. This unpublished thesis was undertaken at Carleton University School of Social Work in Ontario. Couillard's (14) previously cited historical study of the concept of relationship in social work is the most complete recent study found. A perusal of titles of more than 300 theses completed recently in social work revealed no additional studies devoted to the elements 
of the casework relationship.

The foregoing review of the elements of the casework relationship, while not exhaustive, does suggest that there is not yet complete agreement on which elements are most important, which could be included as prerequisites, and to what extent they can be separated. Nor is the re yet a common nomenclature precisely classifying the elements. This imprecision leads to a continuing overlapping and confusion in discussing the elements. Nevertheless, Biestek has brought together what he considers seven elements of the casework relationship. While recognizing that in practice they cannot be separated, he has presented in a theoretical framework a delineation of each element which facilitates teaching and, hopefully, practical application.

In this first chapter a brief presentation has been made of the problem presented to the thesis group by the Orientation Center. Biestek's elements of the casework relationship, as well as the points of view of other writer $s$, have been examined. This suggests some of the problems to be encountered in devising an instrument to test effectiveness of teaching the principles of casework in the Orientation Center. The summary of the literature reviewed here did not cover the technical literature relating to testing, test construction, and statistics which will be treated more appropriately in the chapter on test construction. 
There will be a discussion of the development and construction of the tests, its administration to the trainees at the Orientation Center, and the statistical analysis of the test in the following chapter. 


\section{CHAPTER II}

\section{TEST CONSTRUCTION}

Continuous evaluation and research are needed to insure social service agencies that their methods of training are resulting in higher standards of service. A focus in social work literature has been upon a need for increasing knowledge and upon methods of teaching and applying casework principles. There has been very little emphasis upon testing and evaluation to determine whether the methods are effective. Only one recently completed thesis was found which undertook an examination of in-service training in public assistance with some attention to problems in orientation and induction of new workers. This was the unpublished masters' thesis completed by Merrill (29) in 1965.

In "Evaluation of Staff Training Programs," Weiss (30, p. 11) points out that administrators approach evaluation with various purposes in mind but the most productive approach is the one with improvement and development of programs in mind. She suggests a variety of methods of evaluating training programs, such as rating the trainee's satisfaction with the training, but she found many reported methods of evaluation of limited usefulness in improving 
programs. Two methods she suggests as having merit are the measurement of before and after training of changes in trainee knowledge of concepts and changes in attitudes. She points out that there are tests for measuring changes in attitudes but makes no mention of before and after training tests of knowledge.

In order to formulate a tool for testing at the Orientation Center, a survey was undertaken of test construction material in related fields. The field of education has done a preponderance of research in the preparation of tests. The literature was reviewed for the purpose of gathering ideas and canons for test construction, and it is both too comprehensive and specific for reporting within the purposes of this study. The work of Hedges (32) "Testing Today: How to Construct a Good Multiple Choice Test," and Adkins (33) "Construction and Analysis of Achievement Tests, "were found to be most pertinent to the formulation of test items.

It is generally recognized that the multiple choice test is the most versatile of the objective type tests, The instrument, designed to measure learning at the Orientation Center, was made up of both multiple choice questions, which allow a value judgment or opinion, and true-false questions. The aim was to measure the knowledge and attitudes of the trainees about Biestek's seven elements of the casework relationship and their ability to apply this material to simulated casework situations. During their training, they had been 
given a mimeographed summary of Biestek's social work concepts. Two articles by Biestek (5, 31) were assigned and his book The Casework Relationship (4) was made available to them. Through their class discussions this material was related to actual cases and an individual written assignment, covering the principles of the casework relationship, was required of the trainees.

In order to measure learning, a test was to be constructed and given twice to each group: once as the trainees entered the Orientation Center, and again after the program was completed. The fact that the orientation program lasted only four weeks was a matter of concern because of the complexity of the concepts introduced to the trainees.

The general interrelated nature of Biestek's principles had to be elicited and the applicability to case situations as well. The test as a whole, therefore, would have to be considered as the measurement of trainee comprehension and not any parts of the test.

\section{FORMULATION OF QUESTIONS}

Questions for the test were developed according to the rules of Hedges (32) and Adkins (33). In developing questions, ambiguities and contradictions were avoided, as were indefinite qualifying words. Questions and choices of answers were designed to give the trainee what he needed to know to answer correctly provided that he had 
knowledge of the Biestek principle involved.

Reliability was a primary goal for the test which was designed to be a power test of knowledge of Biestek's principles, as taught in the training course. Thus Biestek's interpretation of the basic social work principles was deferred to in deciding on the correct answer for each question. Guidelines used in test construction are contained in Appendix A.

A significant portion of the available time was spent by the group in the construction of the test questions. After the criteria for test construction were agreed upon and accepted, the same assignment was undertaken by all members; Each person constructed a series of questions on each of the seven elements of the casework relationship as set forth by Biestek. For four weeks the group met once each week to work on questions submitted by each member. Decision on acceptability of each question was unanimous but, if there was dissent, the question under discussion was reworked until unanimity was reached or the item was discarded.

Formulation of questions proved to be a difficult task because of the imprecision and overlapping of the concepts being used as the basis. Questions built around Biestek's definition of a specific element were more easily worked out by the group than those questions which attempted to apply a specific principle to a case situation. Many questions of this latter type required an inordinate amount of 
group effort to make them acceptable. In spite of the attention that casework principles have received in the social work literature, with many authors attempting to clarify and define them, they proved difficult to apply in the test situation due to their indeterminant character.

One hundred and seventy-two questions were finally agreed upon by the project members. Of these, 58 were multiple choice and 114 were true-false questions. This number was considered sufficient for two forms of the pretest which were planned.

\section{GENERAL TESTING DESIGN}

After the questions were formulated, they were put in test form and planning was initiated to proceed with the actual testing. The test was divided equally into two forms which were designated as Test $A$ and Test $B$ of the pretest. A total of ninety-six questions, thirty-four multiple choice and sixty-two true-false, were used in each form. The first ten multiple choice and the first ten true-false questions were identical in each version. Illustrative questions of each type are included in Appendix B. The tests themselves cannot be shown at this point because of their use in the next study.

The plan for giving the test was this: The two forms, A and $B$, were: administered to caseworkers just completing their fourweek training session at the Orientation Center in May, 1968. After 
the pretests, the questions were then corrected by the thesis group and analyzed. From the results of this operation, two forms of the test were constructed and designated as Test AII and Test BII. These versions wereadministered to the two experimental groups from which our data was to be collected. Two tests of equal weight were to be the finished product of the thesis project.

The two experimental groups both consisted of newly hired caseworkers assigned to the Orientation Center. The test was given during the summer to these caseworkers who comprised the two classes for sessions of four weeks each beginning successively in July and August, 1968. Caseworkers in each session were divided at random into two groups which then took the tests before training began and after training was completed. Table I show the testing plan for the administration of Test Forms AII and BII to groups 1 and 2 of Session I and Session II.

TABLE I

TESTING PLAN FOR ADMINISTERING TEST TO SESSIONS I AND II

\begin{tabular}{|c|c|c|c|c|c|}
\hline & Sess & ion I & & Ses: & on II \\
\hline & $\begin{array}{c}\text { Before } \\
\text { Training }\end{array}$ & $\begin{array}{c}\text { After } \\
\text { Training }\end{array}$ & & $\begin{array}{c}\text { Before } \\
\text { Training }\end{array}$ & $\begin{array}{c}\text { After } \\
\text { Training }\end{array}$ \\
\hline Group 1 & AII & BII & Group 1 & AII & AII \\
\hline Group 2 & BII & BII & Group 2 & BII & BII \\
\hline
\end{tabular}


The experimental design shown in Table I was set up to give the most accurate indication of our statistical measures. It was originally planned also to give a final test to a third experimental group in the early fall after further revision of the questions. However, pressure of deadlines and scheduling at the Orientation Center made this impracticable. The cross-over design in the original testing plan was not used with the result that one set of comparisons was lost. This was the comparison of the test with itself on a before and after training basis.

The actual testing procedure followed is shown in Table II. Because of the testing procedure initiated, it was necessary to compare Test AII with Test BII to determine whether they were of equal weight.

TABLE II

ACTUAL TESTING PROCEDURE

\begin{tabular}{lccccc}
\hline & $\begin{array}{c}\text { Beforsion I } \\
\text { Training }\end{array}$ & $\begin{array}{c}\text { After } \\
\text { Training }\end{array}$ & & $\begin{array}{c}\text { Session II } \\
\text { Before } \\
\text { Training }\end{array}$ \\
Group 1 & AII & BII & Group 1 & AII & BII \\
Group 2 & BII & AII & Group 2 & BII & AII \\
\hline
\end{tabular}

The possibility of a difference between the two sessions had to be taken into account since this would affect the comparison between 
Test AII and Test BII. The differentiating ability of the test was evaluated by comparing test scores before training and after training was completed.

\section{PURPOSES OF THE PRETEST}

Purposes of this test trial were to evaluate each question in terms of first, the clarity of language and second, the difficulty. Because of the nature of the material tested, it was important for the questions to be clearly understood. A further purpose was to appraise the test for efficiency. It was desirable to have an instrument designed that could test the student's knowledge of casework concepts in an appropriate length of time. One that could be completed by everyone in sixty minutes was sought. The initial testing session was also used to determine the measure of difficulty of each test item so that two equally balanced, reliable instruments could be formulated from the initial test questions. Each test question could be evaluated in terms of its differentiating power, i. e., whether it could distinguish between the top and bottom trainees. This would further enable elimination of non-discriminating test items, unless purposely retained for psychological purposes. 


\section{IV, ADMINSTRATION OF THE PRETEST}

After the final forms of the pretest were completed, arrangements were made to administer forms $A$ and $B$ to sixteen trainees at the Orientation Center who were just completing their training in May, 1968. In order to control variables, the testing procedures for administering the test were standardized.

The group of sixteen caseworkers was split at random into two groups of eight, one-half taking Test $A$, the other half taking Test $B$. Just prior to administration of the test, a uniform sheet was provided to each trainee to collect personal data about age, sex, education, and previous experience. Also included on this sheet, which is included in Appendix $C$, were general instructions for responding to the questions. Verbal instructions were prepared in advance to be read to the trainees at the time of the test to insure clarity and uniformity in instructions given. Instructions were presented to both groups simultaneously by one test administrator, who followed the predetermined routine, as shown in Appendix $D$.

The respondents were asked to place an asterisk by the ques tions that they found unusually difficult, ambiguous or in need of further clarification. A blank page was provided at the end of the test so that they might make comments about individual test items or about the test as a whole, and they were asked to give their subjective. 
reactions to the test. After the trainees left the test room they were asked individually to rate the test on a questionnaire which was designed to evaluate both test content and procedure. The questionnaire was based on a continuum scale which would give some indication of the trainee's response to characteristics of the instrument such as comprehensiveness, difficulty, fairness, clarity of text, clarity of instructions and time allowed. The evaluative questionnaire may be found in Appendix E.

The trainees were given two hours to complete the examination. The time of completion was recorded on the front of each test so that a closer approximation could be made of the length of time required for a test of this type and number of questions. Both Test $A$ and Test $B$ were scored independently by two members of the thesis group to assure accuracy. The errors were then recorded to facilitate a statistical analysis of the results, and responses on the posttest questionnaire were tabulated.

\section{ANALYSIS OF THE PRETEST}

In order to assess the two tests in terms of reliability, the split-half method was employed. Errors for odd and even questions were correlated on each test as described by Thorndike and Guilford in Selltiz (34, p. 175). 
Traditionally it has been held that in the split-half method, the test of measurement should be split into halves, each of which represents a total test in all significant respects. The usual method of obtaining presumable equivalent halves is to assign the even-numbered items to one half, the oddnumbered to the other. The correlation between the scores on the two parts is then regarded as an estimate of the equivalence coefficient of the test half as long as the original test. From this, an estimate of the coefficient of equivalence of the entire test, known as corrected split-half reliability, can be computed by means of the Spearman-Brown formula.

If both tests proved to be internally reliable and were of equal weight, little revision of the test questions and the tests themselves would be necessary. However, the split-half method gave a cor:rected correlation coefficient of . 48 on Test A and . 74 on Test B. The 5 per cent level of confidence is . 707, indicating that there was insufficient probability that Test $A$ was internally reliable and Test $B$ had only moderate internal reliability. This indicated that revisions of the tests were necessary.

The standard procedure of lengthening the test to improve reliability was not used due to the desire to obtain an efficient instrument, that is, one that could be administered within one hour.

Hence, an item analysis was undertaken to determine which questions were most discriminating and difficult.

A table was constructed which listed the total errors of each trainee in rank order, as well as their scores on each individual question. By consulting the table, a graphic picture of each test item in relation to the response of the ranked trainee was available. The 
most frequently missed questions were evaluated in terms of specificity, terminology and clarity. Each question was analyzed by the entire group. The trainees' comment pages, the post-test questionnaires and asterisked questions were used to evaluate the test items.

The item analysis table was used to distinguish the difficulty and discriminatory ability of each question. Questions that showed no distinction between the top and bottom students we re eliminated or revised. The test items were ranked on a scale indicating three separate categories: (1) difficult--those questions in which few correct responses were obtained, (2) discriminating--those questions which showed a high ratio of correct responses by the top students versus the bottom students, and (3) easy--those in which correct responses were generally received.

The thesis group evaluated each test item in terms of the trainees'responses. The correct answer chosen by consensus of the thesis group was at times in direct conflict.with the majority of the trainees. When conflicts arose either within the thesis group itself or in terms of the test responses, Biestek was utilized as the final authority. Further resources used to evaluate test questions included the remarks of the students on the tests themselves and the questionnaire given after completion of the test.

Factors that may have influenced test results were the attitude 
of the trainees at the end of the orientation session, the level of ability of this specific class, and the nebulous nature of the casework concepts. Toward the end of the orientation training session, a member of the state staff of the Public Welfare Commission addressed the group of trainees informing them that there were many people available for their positions. This created a great deal of resentment and anxiety toward the test situation. Some trainees felt that the pretest might be used to eliminate them from the training program. Experience with differences of opinion among the members of the group project itself demonstrated that interpretations of the casework concepts may be largely a matter of individual attitude. Prior acquaintance with other areas of social work, such as corrections or mental health, might tend to produce different patterns of answering the test questions.

In analyzing the efficiency of the test, the data in Table III was collected.

TABLE III

PRETEST EFFICIENCY DATA

Test A Test B

$\begin{array}{llll}\text { Range: } & 46-88 \text { minutes } & \text { Range: } & 48-87 \text { minutes } \\ \text { Mean: } & 65.3 \text { minutes } & \text { Mean: } & 63.6 \text { minutes } \\ \text { Median: } & 64.5 \text { minutes } & \text { Median: } & 57.6 \text { minutes }\end{array}$


The questionnaire indicated that all of the trainees agreed that more than enough time had been given for completion of the test. There were ninety-six items on each of the test forms. The reformulated test was to consist of ninety questions and could, most probably, be completed by all trainees in one hour.

\section{REFORMULATION OF THE PRETEST}

After completion of the analysis of the pretest, the initial test questions from $A$ and $B$ versions were revised, where indicated, and used to formulate tests AII and BII. Attention had been given to the individual answers on all multiple choice questions and it was determined that one numerical answer was not consistently chosen by the majority of the trainees. Thus the guess factor would be kept close to 20 per cent by chance for multiple choice questions and 50 per cent for true-false questions.

The most discriminating questions were incorporated and duplicated in the body of both versions of the revised tests. For psychological reasons, some easy questions were placed at the beginning of the tests. Questions for forms AII and BII of the reformulated test were set up as shown in Table IV.

It was hypothesized that by balancing both tests with questions of similar discriminatory ability, both tests would be of equal weight as well as internally consistent. 
TABLE IV

ORDERING OF ITEMS IN TEST REVISION

\begin{tabular}{|c|c|c|}
\hline $\begin{array}{c}\text { Item } \\
\text { Number }\end{array}$ & $\begin{array}{l}\text { Type of } \\
\text { Item }\end{array}$ & $\begin{array}{l}\text { Degree of } \\
\text { Difficulty }\end{array}$ \\
\hline \multicolumn{3}{|c|}{ Multiple Choice } \\
\hline $1-5$ & Different & Easy \\
\hline $6-29$ & Duplicate & Discriminating \\
\hline $30-40$ & Different & Difficult \\
\hline \multicolumn{3}{|c|}{ True and False } \\
\hline $41-50$ & Different & Easy \\
\hline $51-81$ & Duplicate & Discriminating \\
\hline $82-90$ & Different & Difficult \\
\hline
\end{tabular}

\section{TESTING THE EXPERIMENTAL GROUPS}

The revised tests were given first to a group of caseworkers who had completed their training at the Orientation Center in June, 1968. It would have been desirable to study these test results with a view toward a second revision of our instrument. However, due to the time element involved, the tabulation and analysis of the scores were not completed. Further revision of the test was not accomplished before administering it to the later experimental groups.

During the summer, the tests were administered to two consecutive summer sessions of beginning caseworkers at the Orientation Center. These trainees, beginning their four week sessions in July and August, 1968, made up the experimental groups. The test 
questions followed the pattern set forth in Table IV as previously explained. One form was given at the beginning of their training and the alternate form was given at the end of their training. Variables in the testing situation were controlled by following the same instructions and procedures that were used in the pretest. One member of the thesis group who had administered the first version of the instrument followed through by administering the test to all subsequent groups.

Following the procedure established for the pretest, both test AII and BII were scored independently by two members of the thesis group for accuracy. Again scores were ranked and the trainees' responses to each item were graphed to enable further item analysis. Poorly discriminating questions were eliminated from the scoring procedure but held so that they could be rewritten for the final test form. The statistical analysis was then carried out with results indicated in the next chapter. 


\section{CHAPTER III}

\section{FINDINGS AND CONCLUSIONS}

This study was undertaken to measure the effectiveness of the Orientation Center training program in teaching basic casework concepts. This required the development of a reliable instrument for measuring trainee comprehension of these concepts. The test, in its final form, will be used by the Orientation Center for future evaluation of the effectiveness of this specific segment of its training program.

\section{FINDINGS}

The last chapter delineated chronologically the procedure followed to ascertain the quality of the testing instruments and the improvement in scores before and after training. Table V gives a numerical indication of the errors on the four tests given to the experimental groups. Three statistical tests were used to analyze these findings. For internal reliability, the Pearson coefficient of correlation with the Spearman-Brown correction was used. The $t$ test was used to determine whether the tests AII and BII were of equal weight, A Median Chi-Square was planned to analyze the 
differences between scores of the two tested groups of students.

Finally, another test was used to estimate significance in the scores, before and after.

TABLE V

ERRORS ON TESTS FOR EXPERIMENTAL GROUPS BEFORE AND AFTER TRAINING

\begin{tabular}{ccccc}
\hline & $\begin{array}{c}\text { Number of } \\
\text { Subjects }\end{array}$ & $\begin{array}{c}\text { Range of } \\
\text { Errors }\end{array}$ & Mean & $\begin{array}{c}\text { Standard } \\
\text { Deviation }\end{array}$ \\
$\begin{array}{c}\text { Before Tests } \\
\text { AII }\end{array}$ & 34 & $25-44$ & 31.6 & 4.83 \\
BII & 32 & $17-45$ & 30.6 & 7.33 \\
After Tests & & & & \\
AII & 32 & $19-41$ & 28.5 & 4.76 \\
BII & 34 & $14-36$ & 26.8 & 5.14 \\
& & & & \\
\hline
\end{tabular}

The split-half method to determine internal reliability of the instruments showed a corrected correlation on AII of . 58 and on BII of . 76. Though low, both correlations were significantly different from a zero correlation at the 5 per cent level of confidence. Internal reliability is a measure of the consistency of the difficulty of the questions. The low correlations indicate that the questions throughout the tests may not be homogeneous in terms of difficulty. Internal reliability is thus theoretically low, but for practical purposes is well within the limits of acceptability. 
The coefficient of alienation for Test AII is .815 and for Test BII is . 650. These values are higher than desirable and this may be due to a number of factors that were not controlled. The reformulated test has more odd numbered questions in the easy section of the test and the even numbered questions outnumber the odd on the discriminating and difficult types of questions. This problem will be partially alleviated by a re-randomization of test items.

In attempting to understand the meaning of these low correlations a review of a rough scattergram was made. The scattergram appeared to be rectilinear rather thancurvilinear in nature. The most significant deviation was in the lower range of ability.

Another factor to be considered was that the scores were distributed with a skew toward more errors; hence, greater variability cannot come from harder questions. On the other hand, since on this small group there were only seventeen errors between the upper range and the minimum, in order to test limits for subsequent classes, the items should not be less difficult in nature or number.

In examining the length of the test and the effect this might have on the reliability measure, the standard formula to test the effect on the reliability coefficient of increasing the variability of the universe was computed. To obtain a corrected correlation of minimum desired expectations (.80), the variance would have to be more than doubled. In order to obtain this variance, the test would have to 
be increased in length by a factor of more than five, and this is unrealistic. In order to do this, there would have to be 450 questions on each test. This figure was obtained with the use of the standard formula to test the effect of length on the reliability coefficient.

Since internal reliability, as measured, depends in signficant part on variance, a function of differing abilities, and since the population is highly homogeneous with respect to educational level, minimum abilities, motivation and current preparation, it may be unrealistic to try to differentiate abilities with reference to a narrow field of study. Therefore, the computed correlations may be as high as can be obtained for this type of homogeneous group.

The test questions covered the seven different elements of the casework relationship. The effect of this can be taken into account in examining the acceptability of the internal reliability of the instruments. According to Guilford (35, p. 450) "If a test is heteroge:neous, in the sense that different parts measure different traits, we should not expect a very high index of internal consistency." A knowledge of one of the casework elements might not indicate a complete understanding of all seven elements. Thus the low correlation does not imply that the test is not a usable instrument.

It was hypothesized that there was no difference between the mean of Test AII and the mean of TestBII. The results of the $t$ test with 64 degrees of freedom showed a ratio of .67 for the before tests 
and 1.37 for the after tests, which at the 1 per cent level of significance is less than the critical value of 1.67 on a 2 -tailed test. Therefore there was a non-significant difference between the two means, indicating a probability of greater than 10 per cent that any difference was due to chance. Hence, Test AII was considered of equal weight with Test BII, in testing the two different groups.

A Median Test of Chi Square was initially planned to determine whether a significant difference existed between the trainees in Group Session 1 and Group Session 2. Since inspection of the two medians showed less than one point difference between the scores on the two groups, it was obvious that there was no significant difference between the two groups. Computation of the test for differences between means showed no significant difference as well. This also added further confidence to the findings that Test AII had equal weight with Test BII.

The three previous tests of significance were for the purpose of evaluating the reliability and consistency of both tests with one another and a comparison of the two groups tested in terms of whether they were of the same population. The tests in their final form were to be used for measuring the improvement which had taken place during the period of time at the Orientation Center. It was then necessary to ascertain whether the instruments could discriminate between the scores of the trainees when they initially began their 
orientation and upon completion of their training.

It was hypothesized that trainee scores would improve after training. The $t$ computed was 4.61 with 130 degrees of freedom. This score is greater than 1.31 at the 1 per cent level of significance on a 1 -tailed test. Therefore, the null hypothesis would be rejected and the hypothesis that there would be an improvement in scores was accepted. It was shown that the errors on the first test, prior to training, were 11 per cent greater than the errors on the tests after training was completed. Thus, the two tests were able to discriminate between groups of trainees upon entering the Orientation Center and upon their completion of the program. However, this is a disappointingly small amount of learning and/or teaching as measured by this instrument.

One explanation for the lack of greater improvement may be the test itself. During initial preparation of the tests, at least 75 per cent of individual member's time was spent in analysis, discussion, and study of the casework principles involved. A very careful attempt was made to make questions and concepts clear and understandable. Item analysis demonstrated a significant number of discriminating questions for this size test. An observation which further verifies that the test questions were able to cover the subject matter and yet discriminate was that the three trainees with the M.S.W. degree scored in the upper 10 per cent, while trainees with 
masters' degrees in other disciplines scored lower, indicating that the tests favored familiarity with casework principles.

To further evaluate the tests, a measure of sensitivity was completed. Johnson (36, p. 132) suggests a measure of sensitivity of a test which is attributed to Jackson (37). Called gamma, it is the ratio of the standard deviation of the abilities of respondents on the test to the standard deviation of errors. It bears the following relationship to the reliability coefficient, from which it was computed for test versions. A and B:

$$
\text { gamma }=\sqrt{\frac{\text { Rho }}{1-\text { Rho }}} \text { where Rho is the reliability coefficient }
$$

Test A yielded a gamma of 1.38 and Test B a gamma of 3.17 . Both of these seem to be within acceptable limits according to cases cited, especially for small populations on such a short examination. Test A would appear to discriminate well throughout the range, while Test $B$ would require a difference of practically two more questions for the same sensitivity. This indicates that in order to discriminate between two subjects the scores would have to give a difference of approximately two errors in Test AII and four errors in Test BII. At best, the test does not discriminate between people with adjacent scores. 


\section{PRODUCT}

The purpose of this project was not only to evaluate the amount of improvement during training at the Orientation Center, but also to develop a reliable and efficient instrument for future testing pur poses. This task has been accomplished to some degree; however, there are limitations to the test and refinements must be made.

In order to meet the requirement of efficiency, a desired limit of sixty minutes was set for the test. The experimental groups were allocated two hours for the test but a comparison of time taken to complete the ninety questions revealed that ample time was allowed for a power test. Table VI gives the time range and mean for both forms of the test.

TABLE VI

TIME RANGE AND MEAN FOR TWO EXPERIMENTAL GROUPS

$\begin{array}{rrr}\text { Time Range: } & 34-62 \text { minutes } & \text { Time Range: } 25-73 \text { minutes } \\ \text { Mean: } & 42.84 \text { minutes } & \text { Mean: } 40.17 \text { minutes }\end{array}$

As demonstrated by the table, some students exceeded the sixty minute limit. Originally students were allowed to take as much time as desired to complete the test but, in each case, only one 
student exceeded the sixty minute limit. It is possible that instructions specifically setting this time limit can eliminate this problem without adding pressure on the trainee.

The findings of the thesis group indicated that a test of this length has a limited but usable potential for discriminating between caseworkers' comprehension of casework principles upon entering the training program and upon completion of the program in which Biestek's elements of the casework relationship were stressed. The test could be used in the future to test this segment of the training program either on a group or individual basis.

By inspection of item analysis schedules there appeared to be no significant difference between the discriminating ability of the multiple choice and the true-false questions. Although the test had some internal reliability, in terms of previously established tables of probability, it did not meet the ideal minimum correlation of .80 or .90 .

In view of the measures of sensitivity, reliability between versions, reliability between groups at both the beginning and end of sessions, and between training groups, the relatively low internal reliability can be taken, in part, as indicating that the versions of the test must be taken as a whole. They are not useful with respect to separate components of the casework relationship. A low correlation between groups taking the test at different sessions can be 
expected. Hence, the test cannot be used for close comparison among groups with assurance.

\section{CRITIQUE}

In developing a test which would be efficient to administer both in usage of time and measuring the reaction of trainees, many fac tors had to be considered and dealt with. There was little information on testing techniques, and even less on how to develop test questions which would determine a trainee's knowledge of casework principles and the application of these principles to life situations. Thus the actual type of test questions to be used presented some initial concern.

In applying Biestek's concepts to developing questions, it was found that often there was difficulty in delimiting a concept so that a question could be formulated which would be relevant solely to one element of the casework relationship. Most often the questions necessarily reflected the fact that the elements of the casework relationship are overlapping and inter-related. It was this fact which offered the greatest challenge in the development of test questions. Some concepts received greater emphasis due to this inter-relatedness and this was especially true of "self-determination" and the "non-judgmental attitude." In applying the concepts to actual ques tions, the questions were constructed to give enough components of 
a situation to make it clear, but not so many components that the question would be self-answering.

It was recognized that there would be differences in the understanding of Biestek's conception of the elements of the casework relationship on the part of the individual instructors and differences in the emphasis they placed on the material. Wide differences in the trainee population, due to past work and educational experience, were noted and it was assumed that these would influence scores. To maximize control of this possible effect on the overall scores, the tests were distributed to the trainees on a random basis.

Motivation of the trainees was another variable which should be noted. Anxiety within the pretest group may have been a factor influencing their motivation and hence their performance. They took the test shortly after they had been told by a state staff member that there were many people available for their positions. Trainees in all test groups were told before they took the test that their performance would not be used as a means of judging them individually. Motivation and performance might have been higher if they had believed they would benefit by greater personal investment.

Time was a problem in developing and refining the test since the Orientation Center schedules its classes at approximately six week intervals. The size of the classes varies from as few as eight members to over thirty. These two factors limited the number of 
persons who could be tested within the time allowed for this study.

Only one pretest was possible, because of the time limitation imposed on the researchers by the conclusion of the school year. Data was gathered by administering the improved form of the test to two orientation classes which were held during the summer months. Analysis of the data was performed during the fall and winter of 1968-69. It would have been desirable to formulate additional questions for the test, to administer alternative forms of the test and to give it to a larger trainee sample, had time been available.

Another criticism is that the original cross-over design, referred to in detail in the previous chapter, was not followed so that one set of comparisons was lost. It had been intended to give a final test in the early fall, but pressure of deadlines and the Orientation Center schedule precluded this.

Care should be taken in interpreting the test results because of the limited number of questions which differentiate between high score and low score trainees. There is not enough difference between individual scores to allow a precise evaluation of the competence of any individual in the test group within adjacent ranks.

Another factor which should be noted is the possibility of memory effect and test familiarity since there was an interval of less than four weeks between the first and second test, and both 
forms of the test contain some duplication of questions. However, this may have been minimized by withholding the correct answers and the scores.

Notwithstanding the obstacles enumerated above, the reliability studies on the test data indicate that both forms of the final test were internally reliable, within the limits indicated earlier, and gave highly consistent results in practice. It should be noted that the reliability pertains to the test as a whole and not to the individual questions.

From the analysis of findings, several suggestion for new approaches emerged. The Orientation Center should consider developing a test on the whole course and not segments of the course, in order to have the variance required for predictive efficiency and for test reliability. During the training program more effort might be spent on discriminating among principles as they apply to concrete situations facing the caseworker. The test would then discriminate better among abilities, and the learning would be more closely related to practice. Finally, the Orientation Center should not try to discriminate abilities narrowly and closely, since it is unlikely in the near future that a test can be developed to do this, despite appearances, and because trainees are already highly selected. 


\section{IMPLICATIONS}

The social work profession has not yet arrived at a satisfactory examination procedure for assessing professional competence. A national committee $(38, p .12)$ is now at work on the problem but, so far, it has only established categories for assessment and has not begun to prepare an examination.

The social work field has been slow in developing means for measuring professional competence. Meaningful testing on a national level has been especially difficult because of differences in schools, variety of work experience, and differences in basic philosophy. The personality of individual social workers must also be taken into account; social work techniques effective for one person may not necessarily be effective for another. Furthermore it is difficult to determine from responses to test questions what a person will actually do in practice.

Much work remains to be done in developing a meaningful testing instrument. The present test described in this study needs to be validated and a larger number of questions needs to be constructed. Casework concepts need to be clarified, particularly with reference to overlap. Different versions of the present test as well as objective tests for other aspects of orientation need to be developed. After the validity of the test has been established, through 
further research, emphasis can be placed on various aspects and goals of teaching. Teaching techniques can be developed through experimentation with different methods of teaching.

It is apparent from the study that social work must develop its goals, its concepts, its knowledge base, and the relationship of these to practice in a more systematic, reliable, and valid way. In any event, studies need to be undertaken to demonstrate how much we know of these matters and whether or not our understanding of them is satisfactory. The casework principles themselves are in a state of flux and change so that what is being measured now may be modified later.

\section{NEED FOR FURTHER RESEARCH}

Much needs to be done about further research in the area of evaluating present casework relationship concepts and methods of training and education for social work as stated above. Additional research is needed to validate the findings of this study and to further develop and refine the test. Further research is needed to determine whether or not the instrument that has been developed here measures what is desired in a caseworker and whether it can accurately predict the performance of the worker. The Oregon State Public Welfare Commission has given permission to re-test the trainees who are still employed by the agency at the end of one year. 
It is anticipated that graduate students at the School of Social Work, Portland State University will undertake additional research in order to refine and determine validity of this newly developed instrument.

It is hoped that the research represented in this study has made a contribution to the field of social work by clearly pointing out the need for and difficulties in evaluation of existing training programs for those who are entering the field at the level of direct service to clients. The study shows the great need for developing more succinct definitions of the elements of the casework relationship in order to teach the concepts more effectively and to test comprehension of these concepts. The study may be the stimulus for further research leading to more objective and valid testing in other aspects of training for social work. Constructing an instrument that reliably tests the comprehension of casework principles is only the beginning.

The task undertaken in this study was to assess the effectiveness of teaching casework principles to new workers at the Oregon State Public Welfare Orientation Center. The concern of the staff at the Orientation Center about how adequately they are preparing new workers for public welfare service is one which is shared by professionals in the field of social work as the need for trained workers rises precipitously. The demands of the training program leave too little time for the staff to develop methods of evaluating and testing the results of their training efforts. 
This study is the beginning of what can become an objective means of answering questions about the ways in which the Orientation Center training program can yield the greatest return in terms of worker knowledge and competence. Perhaps an even greater value lies in the questions it has raised concerning the reliability, the validity in application, and the suitability of concepts held by the profession to be central and underlying. 


\section{BIBLIOGRAPHY}

\section{REFERENCES CITED}

1. Lancelot, Yolanda. "Staff Training as an Integrating Factor in Agency Structure, " Public Welfare, XXII (October, 1964), $263-68$.

2. Weschner-Salzberger, Lotte, Mohilever, Monica, and Kugelmass, Shlomo. "A Short Term Staff Development Project in Israel, " Social Work, 7 (October, 1962), $73-7$.

3. Wolfe, Corinne H. "Training Goals in Public Assistance," Social Casework, XXXVII (February, 1956), 68-75.

4. Biestek, Felix P. The Casework Relationship. Chicago: Loyola University Press, 1957.

5. - "An Analysis of the Casework Relationship," Social Casework, XXXV (February, 1954), 57-61.

6. Alves, Joseph T. Confidentiality in Social Work. Doctoral Dissertation. Washington, D.C. : Catholic University of America, 1959.

7. Gjenvick, Benjamin A. "The Worker's Position with Respect to Client Self-Determination and Christian Responsibility," In Casework Papers, National Conference on Social Welfare, 1959. New York: Family Service Association of America, 1959. $31-38$.

8. Biestek, Felix P. The Principle of Client Self-Determination in Social Casework. Doctoral Dissertation. Washington, D. C: Catholic University of America, 1951.

9. Aptekar, Herbert H. Basic Concepts in Social Casework. Chapel Hill: University of North Carolina Press, 1941. 
10. Garrett, Annette. Interviewing: Its Principles and Methods. New York: Family Service Association of America, 1942.

11. Hamilton, Gordon. Theory and Practice of Social Casework. New York: Columbia University Press, 1951.

12. Hollis, Florence. Casework; A Psychosocial Therapy. New York: Random House, 1964.

13. Perlman, Helen Harris. Social Casework: A Problem Solving Process. Chicago: University of Chicago Press, 1957.

14. Couillard, Carmen L. "A Historical Study of the Concept of Relationship in Social Casework, 1917-1960," Unpublished doctoral dissertation. University of Chicago, 1966.

15. Irvine, May. "Communication and Relationship," Social Casework, XXXVI (January, 1955), 13-21.

16. Towle, Charlotte. Common Human Needs: An Interpretation for Staff in Public Assistance Agencies. Washington, D.C.: Government Printing Office, 1945.

17. Timms, Noel. Social Casework Principles and Practice. London: Routledge and Kegan Paul, 1964.

18. Daly, Katherine. "Initial Interviews with Clients Who Move Because of Inner Conflict," In Casework Papers, National Conference on Social Welfare, 1959. New York: Family Service Association of America, 1959, $108-119$.

19. Hamilton, Gordon. "Basic Concepts in Social Casework," In Readings in Social Casework 1920-1938. Edited by Fern Lowry. New York: Columbia University Press, 1939, $155-171$.

20. McCormick, Mary J. "The Old and the New in Casework," In Social Casework in the Fifties. Edited by Cora Kasius. New York: Family Service Association of America, 1959. 
21. Simcox, Beatrice R., and Kauffman, Irving. "Handling of Early Contacts with Parents of Delinquents," Social Casework, XXXVII (November, 1956), 443-9.

22. Meyer, Carol H. "Changing Concepts of Individualized Services," Social Casework, XLVII (May, 1966), 279-85.

23. Sipiron, Max. "Family Centered Casework in a Psychiatric Setting," Social Casework, XXXVII (April, 1956), 16774.

24. Fisher, George A., et al. "The Use of Self-Determination and Confidentiality in Casework and Group Work Practice: An Exploratory Study. "Unpublished Masters' thesis. Portland, Portland State College, 1967.

25. Soyer, David. "The Right to Fail," Social Work, 8 (July, 1963), $72-78$.

26. American Association of Social Workers. "Standards for the Professional Practice of Social Work," Social Work, XXII, Part II (July, 1952), 1-15.

27. Sprafkin, Benjamin. "A New Look at Confidentiality," Social Casework, XL (February, 1959), 87-90.

28. Meyer, Paul. "Client Self-Determination." Unpublished Masters' thesis. Ottawa, Carleton University, 1968.

29. Merrill, Lee. "In-Service Training in Public Assistance. Some Perceptions Re: Orientation-Induction Role in Preparing Workers for Their District Assignment. " Unpublished Masters' thesis. Los Angeles, University of Southern California, 1965.

30. Weiss, Carol H. "Evaluation of Staff Training Programs," Welfare in Review, III (March, 1965), 11-17.

31. Biestek, Felix P. "The Principle of Client Self-Determination," Social Casework, XXXII (November, 1951), 36975.

32. Hedges, William D. "Testing Today: How to Construct a Good Multiple Choice Test." Monograph. Charlottesville, University of Virginia, 1965. 
33. Adkins, Dorothy C. Construction and Analysis of Achievement Tests. Washington, D. C.: Government Printing Office, 1947.

34. Selltiz, Claire, et al. Research Methods in Social Relations. Revised ed. New York: Holt, Rinehart and Winston, 1965.

35. Guilford, J, P. Fundamental Statistics in Psychology and Education. New York: McGraw-Hill, 1956.

36. Johnson, Palmer O. Statistical Methods in Research. New York: Prentice Hall, 1949.

37. Jackson, Robert W. B. "Reliability of Mental Tests," British Journal of Psychology, XXIX (1939), 267-87.

38. "Defining and Assessing Competence: A Progress Report," NASW News, 14 (November, 1968), 12-17.

\section{GENERAL REFERENCES}

1. Alder, Henry L., and Roessler, Edward B. Introduction to Probability and Statistics. San Francisco: W. H. Freeman, 1964.

2. Arkin, Herbert, and Colton, Raymond R. Tables for Statisticians. New York: Barnes and Noble, 1967.

3. Biestek, Felix P. "The Non-Judgmental Attitude," Social Casework, XXXIV (June, 1953), 235-9.

4. Bernstein, Saul. "Self-Determination: King or Citizen in the Realm of Values, " Social Work, 5 (January, 1960), 3-8.

5. Coughlin, Bernard J. "The Rights of Children, " Child Welfare, XLVII (March, 1968), 133-42.

6. Dixon, Wilfred J., and Massey, Frank J. Jr. Introduction to Statistical Analysis. New York: McGraw-Hill, 1957.

7. Dornbusch, Sanford M., and Schmid, Calvin. A Primer of Social Statistics. New York: McGraw-Hill, 1955. 
8. Feldman, Yonata. "The Initial Investigation in Casework." Unpublished paper presented to a seminar of doctoral students at Western Reserve University, 1960.

9. Jourard, S. M. The Transparent Self, Self-Disclosure and WellBeing. Princeton, New Jersey: D. Van Nostrand Co., 1964.

10. Keith-Lucas, Allan. "A Critique of the Principle of Self Determination," Social Work, 8 (July, 1963), 66-71.

11. Meyer, Carol H. "Staff Development: A Social Work Process in a Public Child Welfare Agency," Public Welfare, XX (April, 1962), 125-31.

12. - Staff Development in Public Welfare Agencies. New York: Columbia University Press, 1966.

13. O'Reilly, Charles T. "Caseworkers' Attitudes and Service to Older Clients," Public Welfare, XXI (April, 1963), $29-31$.

14. Spiegel, Murray R. Theory and Problem of Statistics. New York: Shawn Publishing Company, 1961.

15. Staff Development Guide Series \#2B, The State Orientation Center, Caseworker's Outline of Curriculum and Reading List, Staff Development Division, Oregon State Public

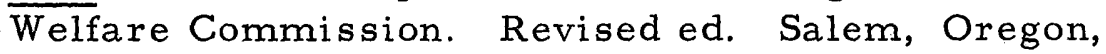
April, 1967.

16. U. S. Department of Health, Education, and Welfare, 1962 Public Welfare Amendments, Social Security Bulletin \#25. Washington, D.C.: Government Printing Office, 1962.

17. - Closing the Gap in Social Work Manpower. Washington, D. C.: Government Printing Office, 1965.

18. - Having the Power, We Have the Duty. The Advisory Council on Public Welfare. Washington, D. C. : Government Printing Office, 1966. 
19. Watson, Edward F. "Training Goals in Public Welfare," Public Welfare, XXIV (April, 1966), 151-58.

20. Wille, Jane. "Goals and Values of Education: Implications for Social Work Education, 1 ... Social Work, 5 (July, 1960), 97-103. 
APPENDIX A

\section{GUIDELINES FOR CONSTRUCTION OF QUESTIONS}

A. Principles of true and false questions

1. Use complete sentences

2. Avoid dependent and dangling clauses

3. Avoid indefinite and qualifying words

4. Sentences should be short and clear

5. Use care in formulating statements

a. Premise can be false

b. Middle part can be false

c. Conclusion can be false

d. If any part is false it is all false

e. The statement must be completely true if the answer is true

f. Omit premise or middle term assuming the student knows these

6. Have a balance of true and false statements

7. Place true and false statements in random order

B. Principles of multiple choice questions

1. Avoid having one answer considerably different from others

2. Make each choice appear equally plausible

3. Choices must be mutually exclusive

4. Assure that the correct answer is not based on opinion or attitude alone

5. Be careful of statements that imply cause

6. Use the same number of answers for all questions; using 5 lessens the guess factor to 20 per cent

7. State the criterion in the question unless it is known

8. Vary the location of the correct answer

9. Construct answers so they can be changed

10. Answers should be in complete sentence form

11. The wording should be consistent from questions to answers 


\section{APPENDIX B}

\section{ILLUSTRATIVE QUESTIONS USED IN TEST}

12. An elderly woman has lived for years in a substandard house. She refuses to move at the suggestion of the worker who thinks her housing is unsafe and unhealthful. The worker should:

a. move her for her own protection.

b. let the matter drop since the woman seems satisfied.

c. respect the woman's desire to remain in her own home.

d. express concern for her and try to persuade her to move.

e. help her to evaluate the advantages and disadvantages of the move.

T $F$ 84. In the final analysis it is the worker who should decide what kind of rehabilitation the client should follow. 
APPENDIX C

INSTRUCTION SHEET

NAME

AGE

SEX

Education Completed Major Minor

Prior Social Work Experience (Yrs., type)

For present employment did you take casework exam. $?$ or college entrance exam. ? (check one.)

Name of present training supervisor

\section{TEST INSTRUCTIONS}

Please choose only one answer for each question. More than one answer may seem correct, but base your answer on what you think is the most appropriate response to the question.

Two hours have been allotted for this test. Please consider each question carefully. A page is provided at the end of the test for your comments about particular questions concerning clarity, ambiguity, etc.

Please check to make sure that all personal data is complete. 
APPENDIX D

VERBAL INSTRUCTIONS FOR PRETEST

I am Margaret Berweger. My co-worker is Mr. Jerry Juve. In a few minutes a test will be passed to you. Please do not look at the questions. We will read the instruction sheet together. PASS TEST

Do not start the test until told to do so. This is a timed test but you should find that you will not need the entire time allotted. Please do not help your neighbor during the test. READ INSTRUCTION SHEET

Now, will you please fill out the personal data. When you have finished, lay your pencil down.

There are two versions of this test: An "A" version and a "B" version. Your neighbor's test may not be the same as yours. Answer all the questions.

As you go along make a check in the left hand margin beside those questions that give you difficulty. If you have any questions during the test, raise your hand to attract the attention of $\mathrm{Mr}$. Juve or me. If you make an error, please carefully cross it out and put your correct answer beside it.

When you have finished answering all the questions, raise your hand so that the time of completion can be recorded on the test paper. Then use the last page of the test for your comments. When you have finished, hand the test to Mr. Juve or to me. You may leave the room.

NOTE: Check to see if the question is continued on the next page. There are five choices for each multiple choice question.

Are there any questions? PLEASE START THE TEST

Choose the best answer. 


\section{APPENDIX E}

\section{POST -TEST QUESTIONNAIRE}

You have just completed an examination designed to evaluate your understanding of the components of the casework relationship. As a further step in developing and improving this examination, please complete the rating scales below before discussing the examination with others. Place this mark $/$ at a point on the scale representing your rating.

1. DIFFICULTY

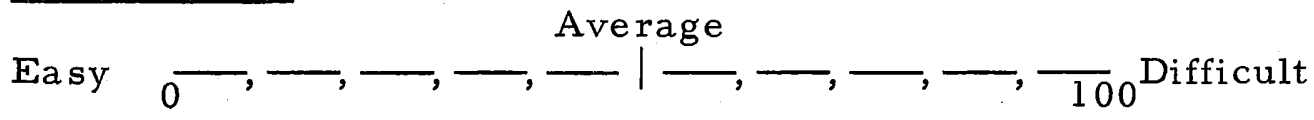

2. COMPREHENSIVENESS (In Covering Concepts)

$\begin{aligned} & \text { Incom }- \\ & \text { plete }\end{aligned},-,-,, \frac{\text { Ave rage }}{-},-,-,, \frac{100}{10}$ Complete

3. FAIRNESS (How well did this test your knowledge of the concepts of the casework relationship?)

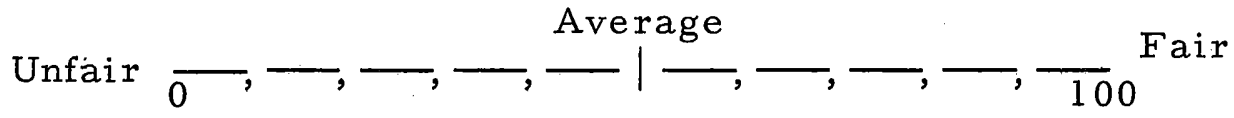

4. CLARITY OF TEXT

Unclear $\_,-,-, \frac{\text { Average }}{-1},-,-\frac{1}{100}$ Clear

5. CLARITY OF INSTRUCTIONS

Unclear $,-,-,-, \frac{\text { Average }}{-},-,-\frac{100}{10}$ Clear

6. TIME (How much time allowed for proper answering?)

Average

Too

little

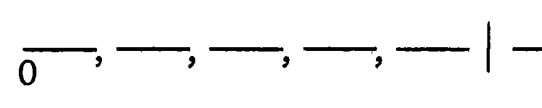

Too much

NAME

DATE 